\title{
Exosomes, endogenous retroviruses and toll-like receptors: pregnancy recognition in ewes
}

\author{
Irene Ruiz-González ${ }^{1}$, Jing Xu ${ }^{1}$, Xiaoqiu Wang ${ }^{1}$, Robert C Burghardt ${ }^{2}$, Kathrin A Dunlap ${ }^{1}$ \\ and Fuller W Bazer ${ }^{1}$ \\ Departments of ${ }^{1}$ Animal Science, Room 442 Kleberg and ${ }^{2}$ Veterinary Integrative Biosciences, \\ 2471 Texas A\&M University, College Station, Texas 77843, USA \\ Correspondence should be addressed to FW Bazer; Email: fbazer@cvm.tamu.edu
}

\begin{abstract}
Conceptus-endometrial communication during the peri-implantation period of pregnancy ensures establishment of pregnancy. We hypothesized that this dialog involves exosomes, ovine endogenous jaagsiekte retroviruses (enJSRV) and toll-like receptors (TLR) which regulate the secretion of interferon tau (IFNT), the pregnancy recognition signal in ruminants. First, exosomes isolated from uterine flushings from cyclic and pregnant ewes were analyzed for exosomal content and uterine expression of heat shock protein 70 (HSC70). Then, conceptus trophectoderm cells (oTr1) treated with different doses of exosomes were analyzed for the expression of genes involved in TLR-mediated cell signaling. The results revealed that exosomes contain mRNAs for enJSRV-ENV, HSC70, interleukins, and interferon (IFN)-regulatory factors. Exosomal content of enJSRV-ENV mRNA and protein decreased from days 10 and 12 to day 16 of gestation, and uterine expression of HSC70 increased in pregnant ewes compared with cyclic ewes. The oTr1 cells proliferated and secreted IFNT in a dose-dependent manner in response to exosomes from cyclic ewes. The expression of $C D 14$, CD68, IRAK1, TRAF6, IRF6, and IRF7 mRNAs that are key to TLR-mediated expression of type 1 IFNs was significantly influenced by day of pregnancy. This study demonstrated that exosomes are liberated into the uterine lumen during the estrous cycle and early pregnancy; however, in pregnant ewes, exosomes stimulate trophectoderm cells to proliferate and secrete IFNT coordinately with regulation of TLR-mediated cell signaling. These results support our hypothesis that free and/or exosomal enJSRV act on the trophectoderm via TLR to induce the secretion of IFNT in a manner similar to that for innate immune responses of macrophages and plasmacytoid dendritic cells to viral pathogens.
\end{abstract}

Reproduction (2015) 149 281-291

\section{Introduction}

The synepitheliochorial placenta of ruminants is one of the least invasive mammalian placentae (Leiser \& Kaufmann 1994). In ruminants, initial attachment of the elongated conceptus (embryo plus its extra-embryonic membranes) does not take place until days 15-16 of pregnancy when binucleate cells $(\mathrm{BNC})$ form and fuse with the uterine luminal epithelium (LE) to create syncytia where placentomes will later develop for the exchange of nutrients and gases (Wooding 1992). Therefore, there is a long pre-attachment phase wherein conceptus survival depends exclusively on its ability to respond to the components of histotroph within the uterine lumen and to influence the maternal environment (Spencer et al. 2004). Interestingly, most embryonic loss in mammals occurs during this periimplantation period of pregnancy (Reynolds \& Redmer 2001, Macklon et al. 2002).

In domestic ruminants, the non-attached elongating conceptus begins to signal its presence in the uterus around days 10-12 of pregnancy by secreting interferon tau (IFNT) which abrogates the development of the luteolytic mechanism and regulates the expression of genes in uterine epithelial and stromal cells (Spencer \& Bazer 1995, Gray et al. 2006, Bazer et al. 2008). However, the mechanisms for initiation of secretion of IFNT by the trophectoderm around day 10 and cessation of its secretion around day 21 have not been elucidated despite the significant role of IFNT in the establishment of pregnancy in ruminants.

In general, interferons (IFNs) represent a cellular response to viral infection by cells of the innate immune system (Trinchieri 2010). The endosomal counterparts of the toll-like receptors family (TLR): TLR3, TLR7, TLR8, and TLR9 (Asselin-Paturel \& Trinchieri 2005, Ito et al. 2005, Akira et al. 2006, Kumar et al. 2009, GonzálezNavajas et al. 2012) induce the secretion of type 1 IFNs upon recognition of viral nucleic acids that travel as complete infectious particles or transported within cellular organelles such as microvesicles/exosomes 
(Diebold et al. 2004, Morelli et al. 2004, Blasius \& Beutler 2010, Dreux et al. 2012). Indeed, researchers are currently focusing on the role of exosomes in the transport of viral components into target cells during the course of an infection (Nguyen et al. 2003, Masciopinto et al. 2004, Pegtel et al. 2010, Meckes \& Raab-Traub 2011) and whether this is a mechanism whereby the virus evades immune surveillance by the host.

Simultaneous with onset of secretion of IFNT, the pre-attached ruminant conceptus is exposed to increasing amounts of single stranded RNA endogenous jaagsiekte retroviruses (enJSRV; Dunlap et al. 2005). The enJSRVs are very abundant in the ovine reproductive tract after being incorporated in the genome throughout evolution (Palmarini et al. 2001) and their expression is known to regulate key peri-implantation events in the conceptus such as formation of BNCs (Dunlap et al. 2005, Dunlap et al. 2006). It is clear that expression of enJSRV and IFNT are temporally related (Palmarini et al. 2001). An interspecies model was used to demonstrate that endometrial enJSRV shed into the uterine lumen of pregnant ewes can infect bovine conceptuses (Black et al. 2010). However, the mechanism whereby enJSRV travels throughout the uterine lumen and incorporates into conceptus trophectoderm remains unknown.

During pregnancy, there is an essential need to avoid a maternal immune response against the conceptus, which makes it very unlikely that enJSRV would travel as free particles. As the release of exosomes by uterine cells has been demonstrated (Racicot et al. 2012, Ng et al. 2013), we hypothesized that the viral particles released by the endometrium during the preattachment phase of pregnancy utilize exosomes to escape maternal immune surveillance and to reach the conceptus. Once exosomes are incorporated into the trophectoderm, we propose that enJSRV activates TLR-mediated immune pathways based on our finding of expression of viral-recognition receptors TLR7 and TLR8 in ovine trophectoderm as well as their regulatory effects on enJSRV and conceptus development (I Ruiz-Gonzalez, M Minten, X Wang, K Dunlap, FW Bazer, unpublished observations). In addition, we hypothesized that activation of TLRs by enJSRV leads to IFNT production in a manner similar to that whereby innate immune cells secrete type $1 \mathrm{IFNs}$ in response to viruses following viral infection (Diebold et al. 2004, Asselin-Paturel \& Trinchieri 2005, Dreux et al. 2012).

The aims of this study with ewes were to i) isolate and characterize exosomes in the uterine lumen; ii) demonstrate uptake of exosomes by trophectoderm cells; iii) determine the effects of exosomes on secretion of IFNT by ovine trophectoderm cells; and iv) identify the expression of the components of the classical TLR-mediated cell signaling pathway for the secretion of type 1 IFNs in conceptus trophectoderm.

\section{Material and methods}

\section{Experimental design}

Mature Rambouillet ewes (Ovis aries) were observed daily for estrus (day 0 is the day of onset of estrus) in the presence of vasectomized rams and used in experiments after exhibiting at least two estrous cycles of normal duration (16-18 days). All experimental and surgical procedures were performed in compliance with the Guide for the Care and Use of Agriculture Animals in Research and Teaching and approved by the Institutional Animal Care and Use Committee of Texas A\&M University.

\section{Collection of samples}

At estrus and on day 1 , ewes were mated to either a vasectomized ram or an intact ram of proven fertility. The ewes were then assigned randomly to be ovariectomized-hysterectomized on day 10, 12, 13, 14, 15 , or 16 of the estrous cycle or day $10,12,13,14,15$, or 16 of pregnancy ( $n=3-5$ ewes per day and status) as described previously (Spencer et al. 1999).

At hysterectomy, uteri were flushed with $10 \mathrm{mM}$ Tris buffer $(\sim 10 \mathrm{ml})$ and pregnancy was confirmed by the presence of a morphologically normal conceptus and a functional corpus luteum $(\mathrm{CL})$. The sections $(\sim 0.5 \mathrm{~cm})$ from the mid-portion of each uterine horn were fixed in fresh $4 \%$ paraformaldehyde in PBS $(\mathrm{pH} \mathrm{7.2).} \mathrm{After}$ $24 \mathrm{~h}$, the fixed tissues were changed twice to $70 \%$ ethanol $(\mathrm{v} / \mathrm{v})$ for another $24 \mathrm{~h}$, dehydrated through a graded series of alcohol to xylene, and then embedded in Paraplast-Plus (Oxford Labware, St Louis, MO, USA). The conceptuses recovered from pregnant ewes on days 13-16 were snap frozen in liquid nitrogen and stored at $-80{ }^{\circ} \mathrm{C}$ for subsequent RNA extraction.

\section{Isolation of exosomes from uterine flushings}

The exosomes were isolated from uterine flushings using the precipitation solution Exoquick (SBI System Biosciences, Inc., Mountain View, CA, USA; da Silveira et al. 2012, Hannafon \& Ding 2013). Briefly, $5 \mathrm{ml}$ of uterine flushing from each ewe were concentrated using Amicon $0.53 \mathrm{~K}$ filter columns (Sigma-Aldrich) and incubated with Exoquick solution at $4{ }^{\circ} \mathrm{C}$ for $16 \mathrm{~h}$ following the manufacturer's instructions. The resulting exosomal pellet was either resuspended in PBS ( $\mathrm{pH} 7.4)$ before RNA extraction or reconstituted in radioimmunoprecipitation assay buffer (Thermo Scientific, Waltham, MA, USA) for protein extraction.

\section{Transmission electron microscopy}

The exosomes isolated from different days of the estrous cycle and pregnancy were reconstituted in PBS and 
Table 1 Primer sequences used for RT-PCR analysis in the exosomes.

\begin{tabular}{llll}
\hline Gene & Accession number & Forward primer & Reverse primer \\
\hline HSC70 & NM_174345 & GACCTGCAGTTGGCATTGATCT & TAGCCTGACGCTGAGAGTCGTTA \\
enJSRV-ENV & AF105220.1 & AACATTTGCAAGGAATTTGG & GCTCCATAAGATGTTGGTGC \\
\hline
\end{tabular}

uranyl-acetate/methylcellulose (UA/MC) staining was performed. Briefly, aliquots from exosomes were transferred to filmed grids and allowed to adsorb for $20 \mathrm{~min}$. The grid was washed with $10 \%$ PBS and exosomes were fixed with $1 \%$ glutaraldehyde for $5 \mathrm{~min}$. The grid was then transferred to uranyl-oxalate for $5 \mathrm{~min}$ and stained with a solution of MC-UA for $10 \mathrm{~min}$. The samples were examined using a FEI Morgagni 268 digital transmission electron microscope (FEI, Hillsboro, OR, USA).

\section{Immunohistochemical analysis}

Immunoreactive constitutive heat shock protein 70 (HSC70) protein was localized in paraffin-embedded samples of cyclic and pregnant uteri using the mouse Vectastain ABC Elite Kit (Vector Laboratories, Burlingame, CA, USA) following the manufacturer's instructions. Briefly, antigen retrieval was performed using boiling citrate, and endogenous peroxidase activity was blocked in methanol with $0.3 \%$ hydrogen peroxide for $15 \mathrm{~min}$ at room temperature (RT). The slides were incubated overnight at $4{ }^{\circ} \mathrm{C}$ with a mouse $\mathrm{MAB}$ against HSC70 (ADI-SPA-820, Stressgen Biotechnologies, Inc., San Diego, CA, USA) at final a dilution of 1:150 in PBS $+1 \%$ BSA. Negative controls included substitution of the primary antibody with purified non-immune mouse immunoglobulin G (IgG) at the same final concentration. Photomicrographs were taken using a Zeiss Axioplan2 microscope fitted with an AxioCamHRc camera (Carl Zeiss, Inc., Thornwood, NY, USA).

\section{PCR}

Total RNA from conceptuses and exosomes was extracted using Trizol (Invitrogen) following the manufacturer's instructions. The quantity and quality of total RNA were determined by spectrometry. When processing conceptus RNA, denaturing agarose gel electrophoresis was also performed. RNA from exosomes $(1.5 \mu \mathrm{g})$ and conceptuses $(2.1 \mu \mathrm{g})$ was reverse transcribed using the SuperScript First-Strand Synthesis System for RT-PCR (Invitrogen) following the manufacturer's instructions. Control reactions in the absence of reverse transcriptase were prepared for each sample to detect genomic DNA contamination. The resulting CDNA was stored at $-20^{\circ} \mathrm{C}$ for further analysis.

Exosomal content of mRNAs for enJSRV-ENV and $\mathrm{HSC7O}$ was determined using semi-quantitative-PCR as described previously (Dunlap et al. 2005). Briefly, 15 ng of cDNA from exosomes was reverse transcribed using Takara ExTaq (Takara Biotechnology, Dalian, CO, USA) using the primers listed in Table 1. PCR products were separated on a $1.5 \%$ agarose gel and visualized by ethidium bromide staining and u.v. transillumination using a Chemidoc-XRS Multi-imager with Quantity One Software (Bio-Rad).

In addition, quantitative PCR (qPCR) was performed using the ABI prism 7900 HT Fast Real-Time PCR System with Power SYBR Green PCR Master Mix (Applied Biosystems) as specified by the manufacturer. Specific oligonucleotide primers were designed and analyzed by Primer Express Software for Real-Time PCR v3.0 (Applied Biosystems). Also, primers were blasted using the available databases to ensure their specificity for the gene of interest in this study. Forward and reverse primer sequences for all genes analyzed in the exosomes and in the conceptus are listed in Tables 2 and 3 respectively. Primer specificity and efficiency $(-3.22>$ slope $>-3.44)$ were confirmed using a test amplification run. Each individual sample was run in triplicate using the following conditions: $50{ }^{\circ} \mathrm{C}$ for $2 \mathrm{~min}, 95{ }^{\circ} \mathrm{C}$ for $10 \mathrm{~min}$, and then $95^{\circ} \mathrm{C}$ for $15 \mathrm{~s}$ and $60^{\circ} \mathrm{C}$ for $1 \mathrm{~min}$ for 40 cycles. A dissociation curve was generated to determine the amplification of a single product. The threshold was set at the linear region of the plots above the baseline noise, and threshold cycle $\left(C_{\mathrm{T}}\right)$ values were determined at the cycle number at which the threshold line crossed the amplification curve. Ovine alpha-tubulin (TUBA) was used as the reference gene. Mean $C_{\mathrm{T}}$ values for each gene were normalized against average $C_{\mathrm{T}}$ values for the reference gene.

Table 2 Primer sequences used for qPCR analysis in the exosomes.

\begin{tabular}{llll}
\hline Gene & Accession number & Forward primer & Reverse primer \\
\hline enJSRV-ENV & AF105220.1 & GGATCTGGACCCCTCGACAT & TGTCTATGCCTATGCCAATGCT \\
IRF6 & NM_001009741.1 & TGGCTACACAGGGACTCCAAA & CCGGGTGGCATGTTTCC \\
IL10 & U11421 & CCAGGATGGTGACTCGACTAGAC & TGGCTCTGCTCTCCCAGAAC \\
TNFA & EU276079 & ACACCATGAGCACCAAAAGC & AGGCACAAGCAACTTCTGGA \\
ILIB & $X 56972$ & ACAAGATTCCTGTGGCCTTG & AAGTGCTGATGTACCAGTTAGGG \\
\hline
\end{tabular}


Table 3 Primer sequences used for qPCR analysis in the conceptus.

\begin{tabular}{llll}
\hline Gene & Accession number & Forward primer & Reverse primer \\
\hline CD14 & NM_001077209 & CTCAGCGTGCTTGATCTCAG & AAGGGATTTCCGTCCAGAGT \\
CD68 & BC112487 & CAGGGGACAGGGAATGACT & CCAAGTGGTGGTTCTGTGG \\
MyD88 & AJ535320 & TGATCACGTGTTCCAGGTGAA & CCTGAAGCTGGTTCTGAATGG \\
IRAK1 & GQ221044.1 & TTTGATGCCTTCATCTGCTACTG & GCTGCCGGATCATCTCATG \\
IRAK4 & NM_001040555.1 & CACGACTTCTCAGAGGAGCTCAA & ATCACCGCCCGGACACA \\
TRAF6 & FJ422555.1 & GCCCGGGCAGGAATAAA & GGCAGCGCACGTATGTTG \\
NFKB & NM_001034661.2 & GCAAAACCACGAAGAAATAATGG & GGATGGTGGGTCTCTGAAAGG \\
IRF7 & XM_004020143.1 & GAGCAGGAGGCCAAGGAACT & GCGCAGTCGCACAATGC \\
IRF6 & XM_004019737.1 & GAGCTGCCCGACCAGAAG & GCCCACGTGCTGAAGCA \\
IFNT & NM_001009741.1 & TGGCTACACAGGGACTCCAAA & CCGGGTGGCATGTTTCC \\
OAS & NM_001123399.1 & GCTATGGCCCAGGAGGATCT & TGGCATCCAGCATGAGTTC \\
\hline
\end{tabular}

\section{Western blotting analysis}

Protein concentration in exosomes isolated from pregnant ewes was determined using the DC Assay (Bio-Rad). Western blot analyses were performed as described elsewhere (Johnson et al. 1999). Briefly, exosomes from each day of pregnancy $(15 \mu \mathrm{g})$ ovine trophectoderm (oTr1) culture medium $(60 \mu \mathrm{g})$ were dissolved in Laemmli sample buffer (Bio-Rad), heated at $85^{\circ} \mathrm{C}$ for $7 \mathrm{~min}$, and separated on 12 and 20\% SDS-PAGE gels respectively. The proteins were transferred to nitrocellulose membranes (ProtranBA83, $0.2 \mu \mathrm{M}$, GE Healthcare Life Sciences, Pittsburg, PA, USA) and non-fat milk (5\%) or BSA $(5 \%)$ was used as a blocker for $1 \mathrm{~h}$ at RT.

Immunoblotting of exosomes from pregnant ewes was performed overnight at $4{ }^{\circ} \mathrm{C}$ with a MAB directed against HSC/HSP70 (ADI-SPA-820, Stressgen Biotechnologies, Inc.) at a 1:1500 dilution in 2\% BSA and a polyclonal antibody against enJSRV-capsid at 1:12 000 in PBS $+1 \%$ BSA as described previously (Black et al. 2010). In addition, a polyclonal antibody against Calnexin (ADI-SPA-865, Stressgen Biotechnologies, Inc.) was used as a negative control because its expression is associated with cellular organelles and it is not present in exosomes formed via the endocytic pathway (Lotvall \& Valadi 2007). The following day, the membranes were washed in TBS-Tween (Sigma) and a HRP-conjugated goat anti-mouse or goat anti-rabbit $\operatorname{lgG}$ was used at a 1:20 000 dilution and incubated $1 \mathrm{~h}$ at RT. Immunoreactive proteins were detected using Supersignal West Dura Extended Duration Substrate (Thermo Scientific) and quantification of the signal was achieved using a Chemidoc-XRS Multi-imager. A background subtraction method included in Quantity One Software (Bio-Rad) was used to assign a Count $\times \mathrm{mm}^{2}$ (CNT-Global data unit) to each sample. These values are presented as arbitrary units for the purpose of statistical analyses.

\section{Vesicle labeling}

Exosomes isolated from uterine flushings from cyclic and pregnant ewes were labeled using the PKH67
Cell Linker Kit (Sigma Chemical Co.) following the manufacturer's instructions with minor modifications. Briefly, $200 \mu \mathrm{g}$ of exosomes were incubated for $6 \mathrm{~min}$ in a mixed solution of Diluent C and PKH67 dye $(1.2 \mu \mathrm{M})$. The labeled exosomes were washed and centrifuged three times at $4000 \mathrm{~g}$ for $5 \mathrm{~min}$ to remove excess dye and then resuspended in serum-free culture medium before being added to the cells. Diluent $C$ was used as a negative control after being subjected to the same procedures as the exosome pellet.

\section{Cell culture}

An established oTr1 cell line from day 15 conceptuses was used for in vitro studies as described previously (Farmer et al. 2008). The cells were cultured in DMEM F12 that included $10 \%$ fetal bovine serum, $50 \mathrm{U}$ penicillin, $50 \mu \mathrm{g}$ streptomycin, $0.1 \mathrm{mM}$ each of nonessential amino acids, $1 \mathrm{mM}$ sodium pyruvate, and $0.7 \mu \mathrm{M}$ insulin. To study the uptake of labeled-exosomes by oTr1 cells, the oTr1 cells were grown in Lab-Tek four-well chamber slides (NalgeNunc International, Rochester, NY, USA). When oTr1 cells were $70 \%$ confluent, labeled exosomes were added and cells incubated for $2 \mathrm{~h}$ at $37^{\circ} \mathrm{C}$. Afterwards, cells were stained with 4',6-diamidino-2-phenylindole (DAPI). DAPI was not used with control cells to ensure the detection of background signal which could be obscured due to the high intensity of the DAPI signal. Fluorescence and corresponding differential interference contrast images were captured used a Zeiss Stallion Dual Detector Imaging System with Intelligent Imaging Innovations Software (Carl Zeiss, Inc.).

Fluorescence deconvolution of images was employed to verify the intracellular localization of the PKH67labeled exosomes within living oTr1 cells by collecting optical slice images from the basal to apical plasma membrane using a C-APO 63X/1.2 water immersion objective with a $0.5 \mu \mathrm{m}$ step size. The images collected in this way allowed monitoring the vibrational movement of the fluorophore within the cytoplasm of the oTr1 cells. 


\section{Cell proliferation assay}

The oTr 1 cells were subcultured $\left(2 \times 10^{4}\right.$ cells $/ 0.4 \mathrm{ml}$ per well) in 24-well plates (Costar\#3524; Corning, Union City, CA, USA) in a complete medium (i.e., DMEM/F-12 (DMEM/Nutrient Mixture F-12; Gibco BRL)) with 10\% FBS (Gibco BRL), $50 \mathrm{U} / \mathrm{ml}$ penicillin, $50 \mu \mathrm{g} / \mathrm{ml}$ streptomycin, $0.1 \mathrm{mM}$ each for 'nutritionally nonessential' amino acids (NEAA), $1 \mathrm{mM}$ sodium pyruvate, $2 \mathrm{mM}$ glutamine, and $4 \mu \mathrm{g} / \mathrm{ml}$ insulin] until the monolayer reached 30\% confluence and then switched to serumand insulin-free customized medium. After starvation for $24 \mathrm{~h}$, the cells were further deprived from serum and insulin for an additional $6 \mathrm{~h}$. The cells ( $n=3$ wells per treatment) were then cultured in $400 \mu \mathrm{l}$ basal medium that contains $5 \% \mathrm{FBS}$ and $1 \mathrm{ng} / \mathrm{ml}$ insulin at $0 \mathrm{~min}$ as a blank control, and then treated with proteins from the exosomes at selected doses $(0,50$ or $150 \mu \mathrm{g})$. After $48 \mathrm{~h}$, the medium was collected for slot blot analyses to detect IFNT secreted into the culture medium. The cell numbers were then determined as described previously (Raspotnig et al. 1999). Briefly, after removal of the medium, cells were fixed in $50 \%$ ethanol for $30 \mathrm{~min}$, followed by vacuum aspiration of the fixative. The fixed cells were stained with Janus Green B in PBS ( $\mathrm{pH} 7.2$ ) for 3 min at RT. The stain was immediately removed using a vacuum aspirator, and the whole plate was sequentially dipped into water and destained by gentle shaking. The remaining water was removed by shaking, after which stained cells were immediately lysed in $0.5 \mathrm{M} \mathrm{HCl}$ and absorbance readings were taken at $595 \mathrm{~nm}$ using a microplate reader. As described previously (Raspotnig et al. 1999), cell numbers were calculated from absorbance readings using the following formula: cell number $=($ absorbance -0.00462$) / 0.00006926$.

\section{Immuno-slot blot analyses for IFNT}

Secreted IFNT in the culture medium recovered from treated oTR1 was measured using a protein slot blot technique. Protein concentration in the medium was determined using the Bradford protein assay (Bio-Rad) with BSA as the standard. Briefly, $300 \mu \mathrm{g}$ samples of total protein were incubated at $96^{\circ} \mathrm{C}$ for $10 \mathrm{~min}$, and slot blotted on to a nitrocellulose membrane using a Minifoldl slot-blot array system (Sigma-Aldrich). The membranes were blocked in 5\% fat-free milk in $20 \mathrm{mM}$ Tris, $150 \mathrm{mM} \mathrm{NaCl}, \mathrm{pH}$ 7.5, and 0.1\% Tween-20 (TBST) for $2 \mathrm{~h}$ at RT and then incubated with primary antibody at $4{ }^{\circ} \mathrm{C}$ overnight with gentle rocking. After three washes of 10 min each with TBST, the membranes were incubated at RT for $1 \mathrm{~h}$ with secondary antibody. The primary antibody, rabbit anti-rolFNT polyclonal IgG, and secondary antibody, HRP-linked anti-rabbit IgG (Cell Signaling, Danvers, MA, USA) were used at dilutions of 1:15000 and 1:20000 respectively. The membranes were then washed with TBST as before, followed by development using ECL detection (SuperSignal West
Pico, Thermo Fischer Scientific, Rockford, IL, USA) according to the manufacturer's instructions. Multiple exposures of each slot blot were performed to ensure linearity of chemiluminescent signals. The protein slot blots were quantified by measuring the intensity of light emitted from the immunoreactive slots under u.v. light using a ChemiDoc EQ System and Quantity One Software (Bio-Rad).

\section{Statistical analyses}

Data were subjected to least-squares ANOVA using the Mixed Procedure of the Statistical Analysis System (SAS Institute, Cary, NC, USA). Normality of data and homogeneity of variance were tested using the Shapiro-Wilk test and Brown-Forsythe test. Data were analyzed by least squares one-way ANOVA and post hoc analysis (Fisher least significant difference test). The results obtained from qPCR and western blotting for proteins in exosomes were analyzed for effects of day of pregnancy. The results obtained from analysis of the oTr1 culture medium were analyzed for the effects of treatment dosage. Data obtained from conceptuses were assessed for the effects of day of pregnancy. A $P \leq 0.05$ value was considered to be statistically significant. Data from qPCR analyses are presented as least-squares means with overall S.E.M. and results from western blots are expressed as means for arbitrary units with overall S.E.M. Data from cell proliferation assays and analyses for determining abundance of IFNT are presented as percent change relative to values for controls.

\section{Results}

\section{Exosomes are liberated into the uterine lumen during both the estrous cycle and pregnancy}

Transmission electron microscopy performed on samples from cyclic and pregnant ewes detected 50-100 nm size, cup-like shaped microvesicles compatible with previous descriptions of exosomes (Fig. 1). Semi-qPCR analysis revealed the expression of $H S C 7 O$ and enJSRVENV mRNAs within exosomes isolated from uterine flushings of both cyclic and pregnant ewes (Fig. 2A). When $\mathrm{qPCR}$ was performed on exosomes isolated from

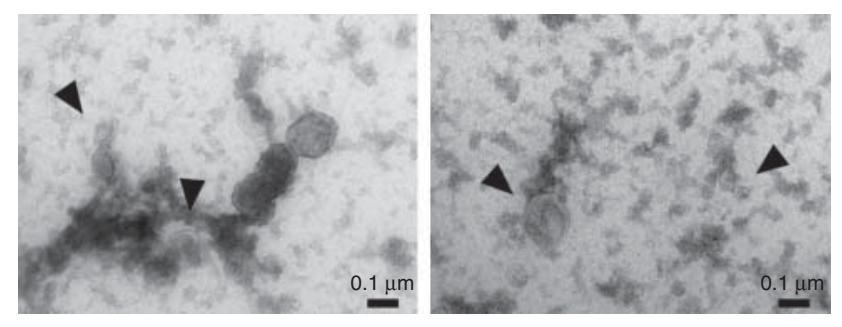

Figure 1 Transmission electron microscopy revealed the presence of 50-100 nm size cup-like shape microvesicles in uterine flushings recovered from cyclic and pregnant ewes. 


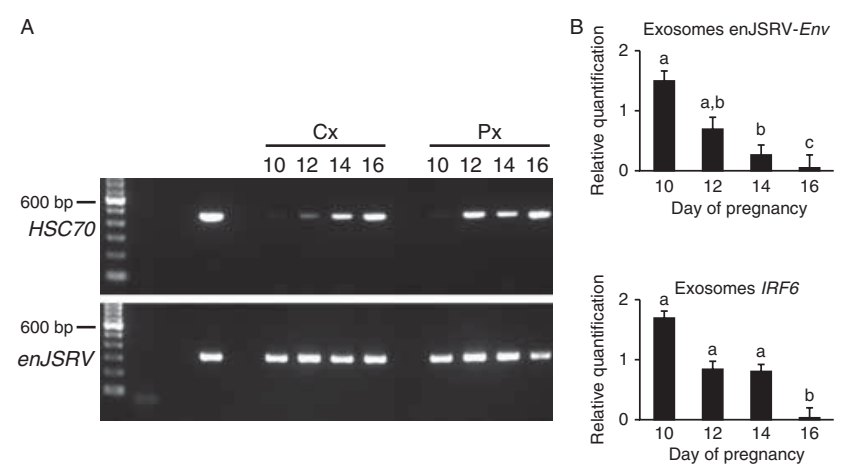

Figure 2 Expression of mRNAs in exosomes isolated from uterine flushings recovered from cyclic and pregnant ewes. (A) Representative RT-PCR analysis of HSC7O and enJSRV-ENV mRNA in exosomes from days 10,12,14, and 16 of the estrous cycle and days 10,12, 14, and 16 of pregnancy. PCR products were separated in a $1.5 \%$ agarose gel and visualized using ethidium bromide. A 100-bp ladder is shown on the left side of the gel. (B) The relative abundance of mRNAs for enJSRV-ENV and IRF6 was analyzed in exosomes recovered on days $10,12,14$, and 16 of pregnancy. Data (least-squares means \pm S.E.M.) are presented as the abundance of mRNA for each gene relative to TUBA. Differences $(P \leq 0.05)$ between days of pregnancy are denoted with superscripts ${ }^{\mathrm{a}, \mathrm{b}, \mathrm{c}}$.

uterine flushings of pregnant ewes (Fig. 2B), the expression of enJSRV-ENV decreased $(P=0.012)$ as pregnancy advanced between days 10 and 16 of gestation. In addition, interferon regulatory factor 6 (IRF6) mRNA decreased in exosomes $(P=0.019)$ from days 10 to 16 of gestation. Furthermore, the expression of interleukin 10 (IL10) and tumor necrosis factor alpha (TNFA) mRNAs was detected by qPCR in exosomes collected from cyclic and pregnant ewes; however, interleukin 1 beta (IL1B) mRNA was not detected (data not shown).

\section{Immunoreactive HSC/HSP70 expression by uterine endometrium differs between cyclic and pregnant ewes}

The expression of immunoreactive HSC70 protein was detected in all uterine compartments, but appeared to be more abundant in uterine LE and glandular epithelium (GE), and stratum compactum stroma (S) (Fig. 3). HSC70 protein was abundant in uterine $L E, G E$, and $S$ on day 10 of the estrous cycle and it remained abundant until day 14 . By day 16 of the estrous cycle, strong staining for HSC70 was limited to stromal cells as it decreased in uterine LE and GE. In the endometria of pregnant ewes, immunoreactive HSC70 was abundant in uterine LE and $S$ on day 10 , but expression was low in uterine GE. The abundance of HSP70 protein increased in uterine $L E, G E$, and $S$ on day 12 of pregnancy and remained abundant until day 16 .

\section{oTr1 cells incorporate exosomes}

Green fluorescent exosomes labeled with PKH67 were visualized within oTr1 cells and some remained in the medium after incubation at $37^{\circ} \mathrm{C}$ for $2 \mathrm{~h}$ (Fig. 4). At $48 \mathrm{~h}$, all fluorescent exosomes were located within oTr 1 cells. Fluorescence was detected in both mononuclear and binuclear trophectoderm cells, with no apparent selectivity for either type of those cell types.

\section{Exosomes carry enJSRV proteins}

Calnexin protein was detected in the uterine endometrium from pregnant ewes, but not in the exosomes

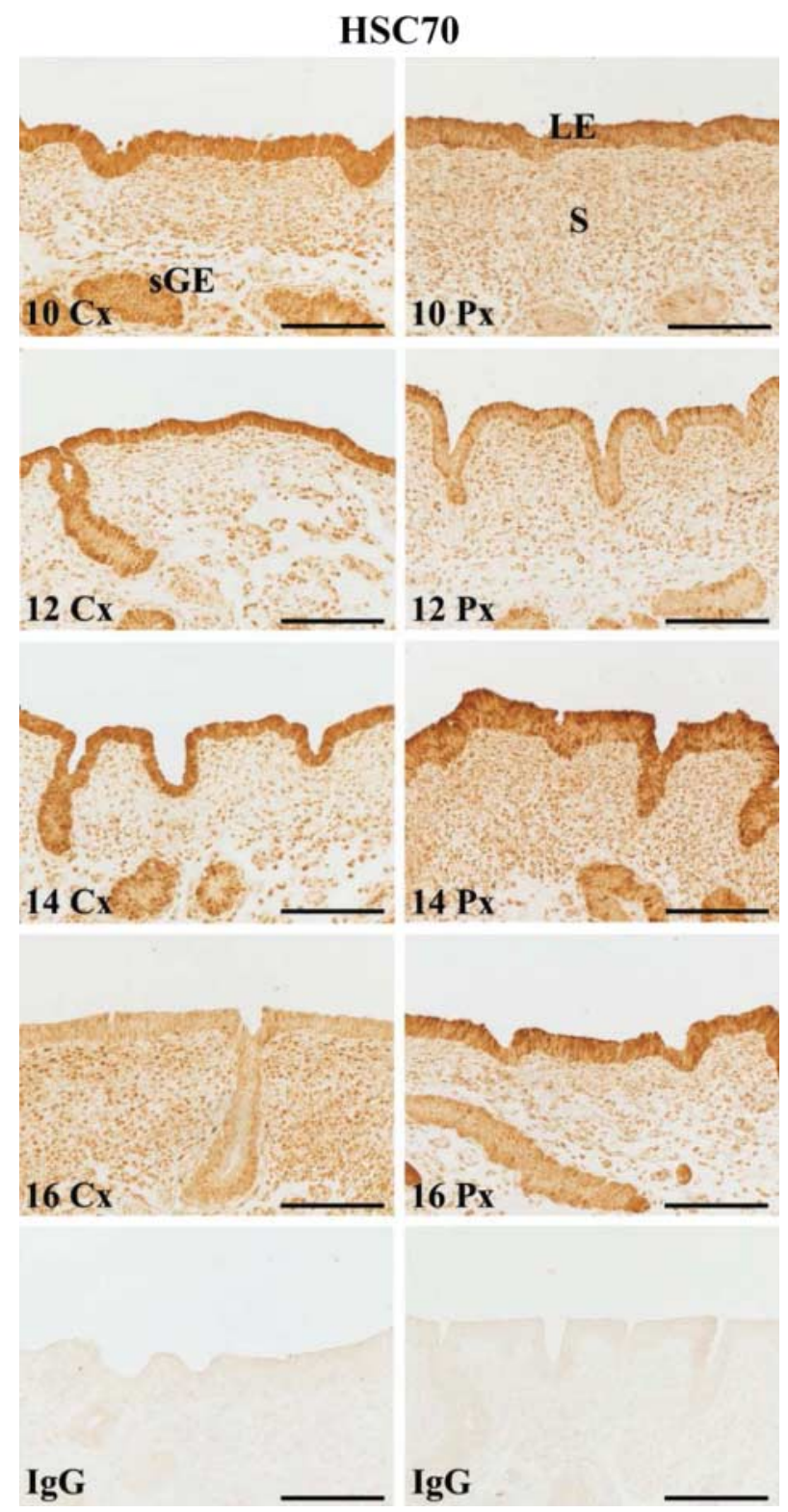

Figure 3 Immunohistochemical localization of HSC70 in uteri of ewes on days $10,12,14$, and 16 of the estrous cycle and days 10 , 12,14 , and 16 of pregnancy. The sections were not counterstained. LE, luminal epithelium; sGE, superficial glandular epithelium; $\mathrm{S}$, stroma. All photographs were from uterine cross sections taken at $20 \times$ magnification using the same width of field (scale bar $=250 \mu \mathrm{m}$ ). 


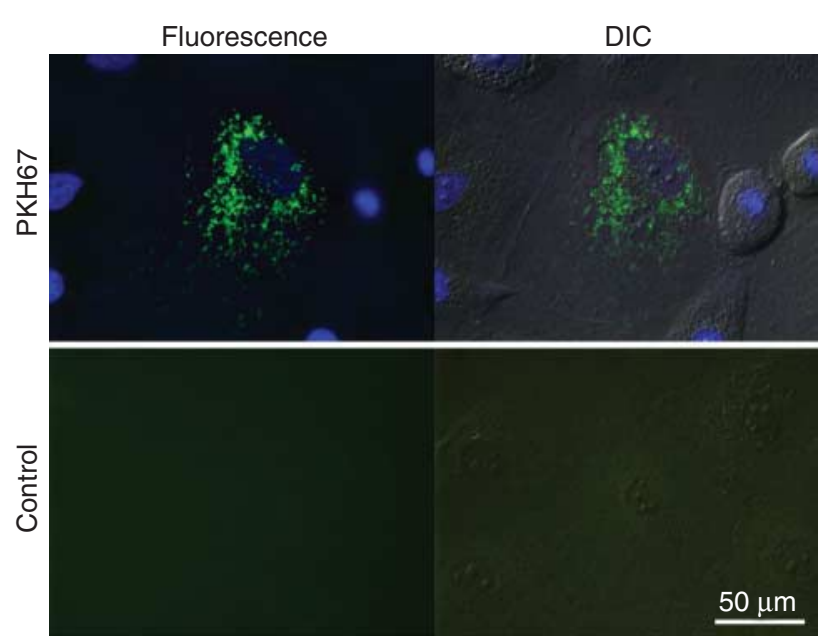

Figure 4 Fluorescence (left panel) and corresponding differential interference contrast (DIC) images demonstrating active uptake of microvesicles by oTR1 cells upon culture with exosomes. The PKH67 green-labeled microvesicles were visualized within the cytoplasm of ovine trophectoderm cells after incubation at $37^{\circ} \mathrm{C}$ for $2 \mathrm{~h}$. No green fluorescent microvesicles were observed in the negative controls (scale bar $=50 \mu \mathrm{m})$.

from those same ewes, which demonstrates the purity of the exosomal samples used in this study. In addition, expression of HSC70 protein, a common marker of exosomes, was found in all samples of exosomes recovered from uterine flushings regardless of day of pregnancy (Fig. 5A). The abundance of enJSRV-capsid protein in exosomes decreased $(P=0.03)$ from days 12 to 16 of gestation (Fig. 5B).

\section{Exosomes stimulate proliferation and secretion of IFNT by oTr1 cells in vitro}

The abundance of IFNT protein in culture medium recovered from exosomes-treated oTr1 cells was assessed by western blotting analyses. The analyses revealed that exosomes recovered from pregnant ewes contained IFNT, which indicated that secreted IFNT was present in exosomes released into the uterine lumen by conceptus trophectoderm. Therefore, exosomes from cyclic ewes were used to assess their effects on production of IFNT by oTr1 cells because they do not contain or carry IFNT. oTr1 cells that were treated with different dosages of exosomes recovered on day 13 of the estrous cycle had higher rates of proliferation and increased production of IFNT (Fig. 6).

\section{Components of the TLR-mediated cell signaling pathway for the expression of type 1 IFNs are expressed by the ovine conceptus during early pregnancy}

The expression of genes known to be involved in cellular TLR-mediated innate responses to viral pathogens was determined from the conceptuses recovered during the time of maternal recognition of pregnancy in ewes (days 13-16 of pregnancy; Fig. 7). Conceptus expression of CD14 and CD68 mRNAs, both considered to be macrophage markers, varied between days 13 and 16 of pregnancy with $C D 14$ increasing from days 13 to 16 $(P=0.08)$, and $C D 68$ decreasing during the same period $(P=0.0002)$. There was no significant change in the expression of $C D 11 B(P>0.05)$, a commonly accepted marker for plasmacytoid dendritic cells.

The expression of myeloid differentiation factor 88 (MYD88), an adaptor protein in TLR-mediated cell signaling pathways, was detected in the conceptus, but the expression was not affected by day of pregnancy $(P>0.05)$. Interleukin receptor-associated kinase 1 (IRAK1) mRNA decreased from days 13 to 16 $(P=0.05)$, while the expression of IRAK4 mRNA was not different due to day of pregnancy $(P>0.05)$. Furthermore, tumor receptor-associated factor 6 (TRAF6) decreased from days 13 to 15 of pregnancy and then increased on day $16(P=0.027)$.

Although the abundance of nuclear factor kappa-B $(N F K B)$ mRNA did not change in conceptuses due to day of gestation, the expression of IRF7 and IRF6 were influenced by day of pregnancy $(P=0.04$ and $P=0.009$, respectively). Moreover, the expression of IFNT and $2^{\prime}$-5'-oligoadenylate synthetase (OAS) mRNAs were not affected by day of pregnancy.

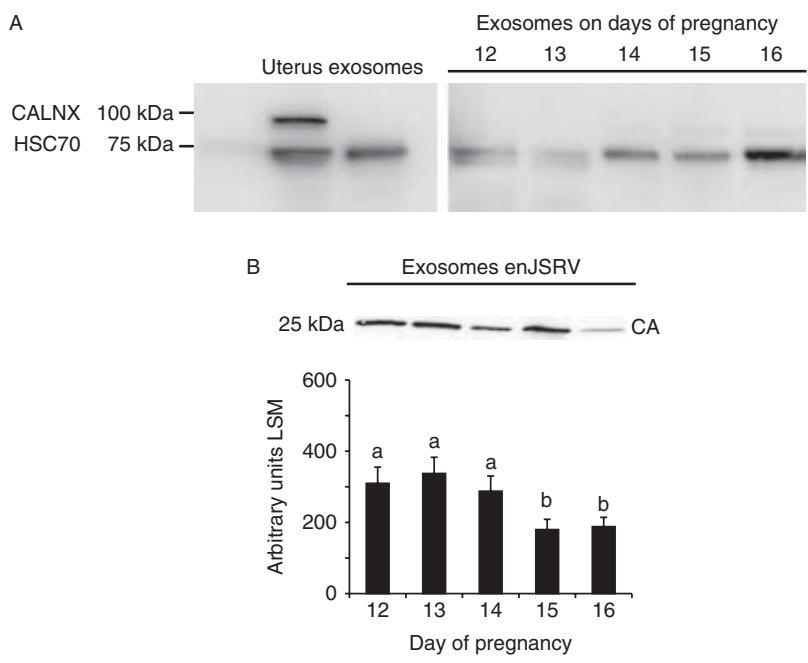

Figure 5 Western blotting analysis of exosomes recovered from pregnant ewes. (A) HSC70 ( 72 kDa in size) is detectable in both exosomes and endometrial preparations, while Calnexin $(\sim 98 \mathrm{kDa}$ in size) is only detectable in the endometrium. (B) Abundance of enJSRV capsid protein $(\sim 25 \mathrm{kDa}$ in size) decreases in exosomes recovered from pregnant ewes as gestation advances from days 12 to 16 .

Data (least-squares means \pm S.E.M.) are presented as arbitrary units. Differences $(P \leq 0.05)$ among days of pregnancy are denoted with superscripts ${ }^{\mathrm{a}, \mathrm{b}}$. CALNX, Calnexin; HSC70, heat shock protein-70; CA, enJSRV-Capsid. 

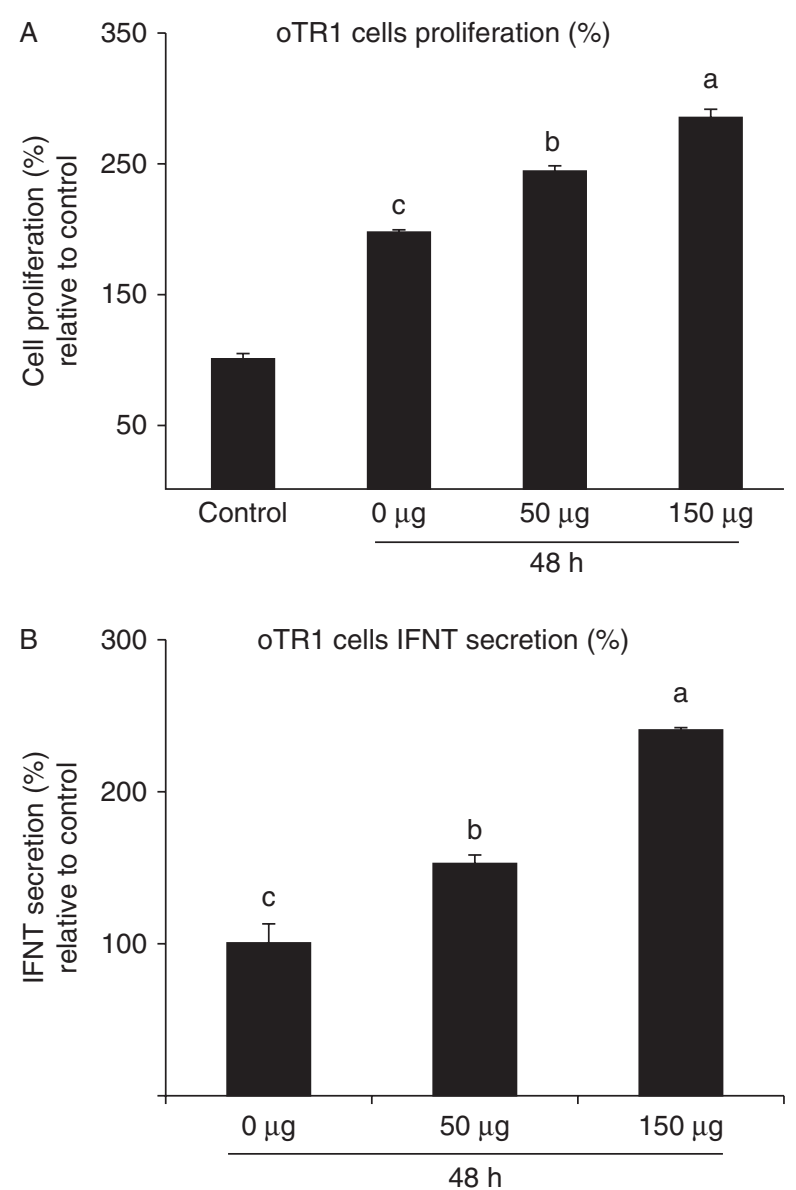

Figure 6 Relative increases in proliferation of oTr1 cells and their secretion of IFNT due to treatment with different dosages of exosomes recovered from day 13 cyclic ewes. Analyses were performed after 48-h in culture. Differences $(P \leq 0.05)$ among days of pregnancy are denoted with superscripts ${ }^{\mathrm{a}, \mathrm{b}, \mathrm{c}}$.

\section{Discussion}

This study provides evidence that exosomes are present within the ovine uterine lumen and that they contain essential molecules involved in key peri-implantational events. In addition, we are the first to report that treatment of oTr1 cells with exosomes stimulates the secretion of IFNT, which is the pregnancy recognition signal in ewes. Moreover, temporal changes in the abundance of exosomal enJSRV during early pregnancy coincide with TLR-mediated activation of production of type 1 IFNs (i.e., IFNT) by conceptus trophectoderm. Furthermore, our results demonstrated that oTr1 cells express the commonly accepted macrophage markers CD14 and CD68 in a regulated manner, as well as express CD11B, a recognized marker for plasmacytoid dendritic cells. Collectively, the results of the present study support our hypothesis that induction of IFNT secretion for pregnancy recognition signaling in ruminants results from an innate immune-like response by
oTr1 cells to maternal enJSRV acting via TLR, particularly TLR7 and/or TLR8.

The recent detection of exosomal microvesicles in human uterine fluid has led to the hypothesis that exosomes participate in the dialog that takes place throughout the uterine lumen between the receptive endometrium and a potential conceptues $(\mathrm{Ng}$ et al. 2013). The ruminant conceptus, which displays a protracted pre-attachment phase during pregnancy, would greatly benefit from this mechanism of cell communication as it is dependent on the components of histotroph during the peri-implantation period of pregnancy. Indeed, Racicot et al. (2012) demonstrated liberation of exosomes by ovine uterine cells in vitro and described the expression of IFNT-related genes in their cargo. Afterwards, another study described the presence of these microvesicles in ovine uterine flushings recovered from day 14 of the estrous cycle and day 14 of pregnancy (Burns et al. 2014). The results presented here are the first to demonstrate that membrane-bound organelles matching features previously described for exosomes (György et al. 2011, Vlassov et al. 2012) are present in ovine uterine flushings as early as
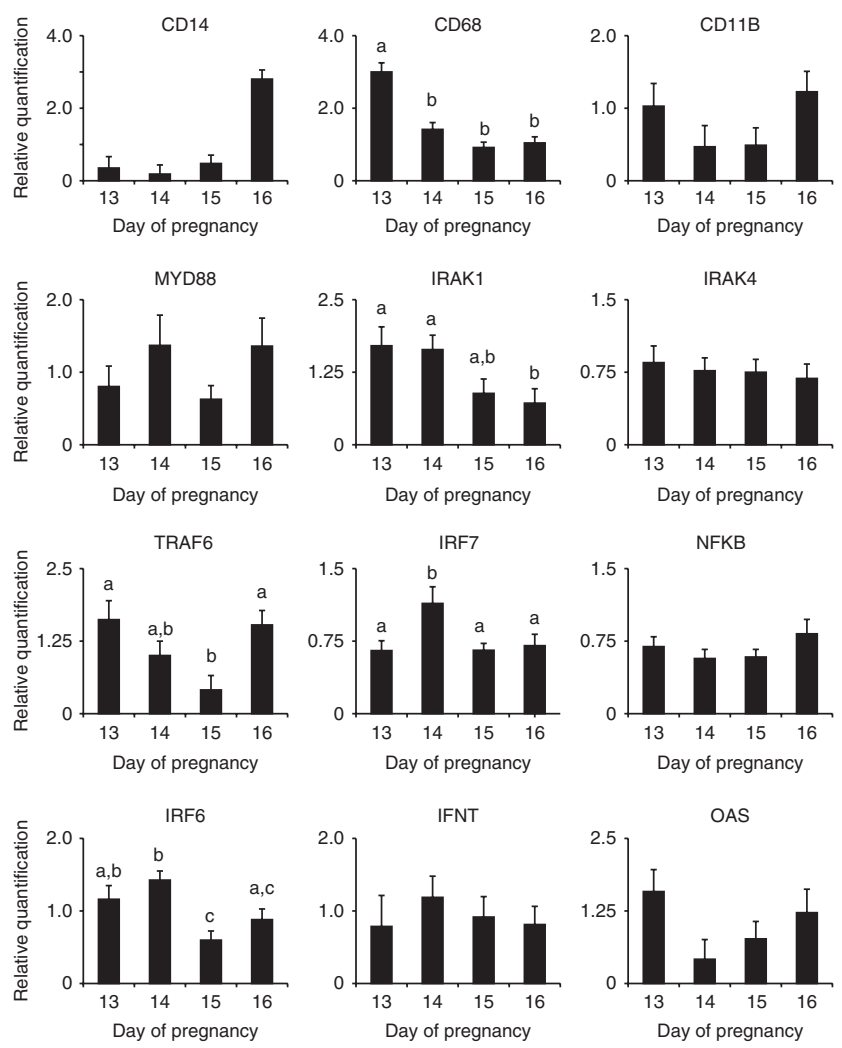

Figure 7 Relative abundance of mRNAs coding for elements involved in the TLR-mediated signaling pathway were analyzed in conceptuses recovered on days 13-16 of pregnancy. Data (least-squares means \pm S.E.M.) are presented as abundance of mRNA for each gene relative to $T U B A$. Differences $(P \leq 0.05)$ among days of pregnancy are denoted with superscripts ${ }^{\mathrm{a}, \mathrm{b}, \mathrm{c}}$. 
day 10 post-estrus/mating, which provide strong support for a role for exosomes in early events responsible for the onset of IFNT secretion and establishment of pregnancy in ewes.

In the current study, characterization of the exosomes recovered from uterine flushings of cyclic and pregnant ewes revealed the presence of multiple mRNAs and proteins likely involved in ruminant reproduction, including enJSRV, IFNT, IRFs, and other cytokines (Spencer et al. 2004, Dunlap et al. 2006, Bazer et al. 2008). Of particular interest is the finding of mRNAs and protein for enJSRV, which supports results published by Burns et al. (2014). It is known that the conceptus trophectoderm contains enJSRV around day 12 (Dunlap et al. 2006) due to the incorporation of viral particles shed from the endometrium (Black et al. 2010). However, the molecular mechanism whereby these particles travel throughout the uterine lumen has not been described. Our results provide evidence for packaging of enJSRV within the exosomal cargo between days 10 and 16 of gestation. These findings reveal an alternative mechanism for viruses to be internalized into the conceptus trophectoderm and for them to influence conceptus development in a manner similar to that whereby pathogenic viruses invade host cells of the innate immune system during the course of infection (Masciopinto et al. 2004, Morelli et al. 2004).

Exosomes are involved in cell to cell communication and they influence signaling pathways in target cells (Février \& Raposo 2004, Lyons-Weiler et al. 2012, Montecalvo et al. 2012). Indeed, our results first demonstrate that treatment of oTr1 cells with exosomes stimulates them to proliferate and secrete IFNT, which indicates that elements within their cargo trigger key peri-implantation events. We propose that exosomal enJSRV initiates immune pathways in the conceptus that induce IFNT production and formation of BNC through proliferative and fusogenic events (Spencer \& Bazer 2004, Dunlap et al. 2006). Supporting this hypothesis, our results indicate that exosomes from pregnant ewes transport enJSRV proteins in a temporal fashion which is similar to their pattern of secretion by ovine uterine epithelial cells (Palmarini et al. 2001). This temporally regulated release of exosomes loaded with viral particles during the critical time of pregnancy recognition supports our hypothesis that enJSRV serves as a potential inducer of both proliferation and secretion of IFNT by oTr1 which is essential for the establishment of pregnancy.

The cellular receptor hyaluronidase 2 (HYAL2) has been proposed to be responsible for the entry of enJSRV into day 12 conceptus trophectoderm (Dunlap et al. 2005, Black et al. 2010); however, HYAL2 is not detected in oTr1 until day 16 of pregnancy (Dunlap et al. 2005). In this study, we analyzed the potential role of TLRs as enJSRV receptors because the members of this subfamily classically mediate the expression of type 1
IFN genes upon viral recognition by cells of the innate immune system (Asselin-Paturel \& Trinchieri 2005, Ito et al. 2005, Akira et al. 2006, Kumar et al. 2009, González-Navajas et al. 2012). We have demonstrated important roles for TLR7 and TLR8 during maternal recognition of pregnancy in sheep (I Ruiz-Gonzalez, M Minten, X Wang, K Dunlap, FW Bazer, unpublished observations), including regulation of IFNT secretion, abundance of enJSRV in conceptuses, and formation of $\mathrm{BNC}$ in the trophectoderm. Indeed, results presented here demonstrate that molecular components of the TLRmediated pathway that induces the secretion of type 1 IFNs in cells of the innate immune system are present in the ovine conceptus trophectoderm during the time that IFNT is being secreted for pregnancy recognition signaling. Coincidentally, we observed temporally regulated expression of $I R F 7$, the major inducer of type 1 IFNs (Honda et al. 2005), and IRF6 in both exosomes and conceptus trophectoderm. In previous analyses, IRF6 was hypothesized to promote proliferation and development of the placenta (Fleming et al. 2009). However, recent results have suggested that IRF6 functions synergistically with maspin to induce differentiation of epithelial cells by regulating exit from the cell cycle and entry into the $\mathrm{G}(0)$ phase of cellular quiescence (Bailey \& Hendrix 2008, Biggs et al. 2014).

Based on results from this study, we propose that TLR7 and TLR8 are key receptors that recognize exosomal enJSRVs and initiate cell signaling for an innate immune cell-like response resulting in synthesis and secretion of IFNT. Further experiments are required to clarify whether and how enJSRV reaches the endosomal compartment of oTr 1 cells to allow TLR7 and TLR8 recognition and processing. Interestingly, HSC70, a common protein marker of exosomes, regulates processing of viral proteins within target cells and promotes cell signaling through TLRs (Wang et al. 2006, Simpson et al. 2008, Kim \& Oglesbee 2012). Furthermore, HSP70 binds to membrane protein receptor CD14 (Asea et al. 2000) which participates in the recognition of viruses in association with TLR (Kurt-Jones et al. 2000, Asea et al. 2002, Baumann et al. 2010). In this study, we provide evidence for temporal changes in expression of CD14 and CD68 in the oTr1, which may allow them to modulate immune-mediated pathways similar to events regulating macrophage activation. Indeed, CD14 and CD68 are monocyte/macrophage markers in ruminants (Mansouri-Attia et al. 2012, Oliveira et al. 2012) that are involved in pathogen recognition, transport of molecules to and from the endosomal compartment and cell adhesion (Ramprasad et al. 1996, Chen et al. 1999, Kurt-Jones et al. 2000), all of which are key events during the peri-implantation period of pregnancy in ruminants (Spencer et al. 2004).

In summary, the results of this study support the hypothesis that exosomes released from the maternal endometrium are involved in events that regulate 
secretion of IFNT and maternal recognition of pregnancy. Our results provide the first evidence for increased production of IFNT by trophectoderm cells in response to exosomes. In addition, we describe temporally regulated changes in the abundance of exosomal enJSRV that are coordinated with expression of key molecules in the conceptus required for TLR-mediated production of type 1 IFNs, such as IFNT. Collectively, these results support our hypothesis that maternal enJSRV transported within exosomes are taken up by the trophectoderm to induce TLR-mediated signaling in the conceptus, which results in the secretion of IFNT in a manner similar to that occurring when cells of the innate immune system respond to viral pathogens.

\section{Declaration of interest}

The authors declare that there is no conflict of interest that could be perceived as prejudicing the impartiality of the research reported.

\section{Funding}

The work of Dr I Ruiz-González was financially supported by a Fellowship for Graduate Courses in Universities and Colleges granted by Caja Madrid Foundation.

\section{Acknowledgements}

The authors thank all members of the Laboratory for Uterine Biology and Pregnancy, Dr Payne at the Image Laboratory (Texas A\&M University College of Veterinary Medicine and Biomedical Science) for performing the electron microscopy, and Kendrick LeBlanc at Texas A\&M University for management of the sheep used in this study.

\section{References}

Akira S, Uematsu S \& Takeuchi O 2006 Pathogen recognition and innate immunity. Cell 124 783-801. (doi:10.1016/j.cell.2006.02.015)

Asea A, Kraeft SK, Kurt-Jones EA, Stevenson MA, Chen LB, Finberg RW, Koo GC \& Calderwood SK 2000 HSP70 stimulates cytokine production through a CD14-dependant pathway, demonstrating its dual role as a chaperone and cytokine. Nature Medicine 64 35-442.

Asea A, Rehli M, Kabingu E, Boch JA, Bare O, Auron PE, Stevenson MA \& Calderwood SK 2002 Novel signal transduction pathway utilized by extracellular HSP70: role of toll-like receptor (TLR) 2 and TLR4. Journal of Biological Chemistry 277 15028-15034. (doi:10.1074/jbc. M200497200)

Asselin-Paturel C \& Trinchieri G 2005 Production of type I interferons: plasmacytoid dendritic cells and beyond. Journal of Experimental Medicine 202 461-465. (doi:10.1084/jem.20051395)

Bailey CM \& Hendrix MJC 2008 IRF6 in development and disease: a mediator of quiescence and differentiation. Cell Cycle 7 1925-1930. (doi:10.4161/cc.7.13.6221)

Baumann CL, Aspalter IM, Sharif O, Pichlmair A, Blüml S, Grebien F, Bruckner M, Pasierbek P, Aumayr K, Planyavsky M et al. 2010 CD14 is a coreceptor of toll-like receptors 7 and 9. Journal of Experimental Medicine 207 2689-2701. (doi:10.1084/jem.20101111)
Bazer FW, Burghardt RC, Johnson GA, Spencer TE \& Wu G 2008 Interferons and progesterone for establishment and maintenance of pregnancy: interactions among novel cell signaling pathways. Reproductive Biology 8 179-211. (doi:10.1016/S1642-431X(12)60012-6)

Biggs LC, Naridze RL, DeMali KA, Lusche DF, Kuhl S, Soll DR, Schutte BC \& Dunnwald M 2014 Interferon regulatory factor 6 regulates keratinocyte migration. Journal of Cell Science 127 2840-2848. (doi:10.1242/jcs. 139246)

Black SG, Arnaud F, Burghardt RC, Satterfield MC, Fleming JA, Long CR, Hanna C, Murphy L, Biek R, Palmarini M et al. 2010 Viral particles of endogenous betaretroviruses are released in the sheep uterus and infect the conceptus trophectoderm in a transspecies embryo transfer model. Journal of Virology 84 9078-9085. (doi:10.1128/JVI.00950-10)

Blasius AL \& Beutler B 2010 Intracellular toll-like receptors. Immunity 32 305-315. (doi:10.1016/j.immuni.2010.03.012)

Burns G, Brooks K, Wildung M, Navakanitworakul R, Christenson LK \& Spencer TE 2014 Extracellular vesicles in luminal fluid of the ovine uterus. PLoS ONE 9 e90913. (doi:10.1371/journal.pone.0090913)

Chen YC, Wang SY \& King CC 1999 Bacterial lipopolysaccharide inhibits dengue virus infection of primary human monocytes/macrophages by blockade of virus entry via a CD14-dependent mechanism. Journal of Virology 73 2650-2657.

Diebold SS, Kaisho T, Hemmi H, Akira S \& Reis e Sousa C 2004 Innate antiviral responses by means of TLR7-mediated recognition of singlestranded RNA. Science 303 1529-1531. (doi:10.1126/science.1093616)

Dreux M, Garaigorta U, Boyd B, Décembre E, Chung J, Whitten-Bauer C, Wieland S \& Chisari FV 2012 Short-range exosomal transfer of viral RNA from infected cells to plasmacytoid dendritic cells triggers innate immunity. Cell Host \& Microbe 12 558-570. (doi:10.1016/j.chom.2012. 08.010)

Dunlap KA, Palmarini M, Adelson DL \& Spencer TE 2005 Sheep endogenous betaretroviruses (enJSRVs) at the hyaluronidase2 (HYAL2) receptor in the ovine uterus and conceptus. Biology of Reproduction 73 271-279. (doi:10.1095/biolreprod.105.039776)

Dunlap KA, Palmarini M, Varela M, Burghardt RC, Hayashi K, Farmer JL \& Spencer TE 2006 Endogenous retroviruses regulate periimplantation placental growth and differentiation. PNAS 103 14390-14395. (doi:10. 1073/pnas.0603836103)

Farmer JL, Burghardt RC, Jousan FD, Hansen PJ, Bazer FW \& Spencer TE 2008 Galectin 15 (LGALS15) functions in trophectoderm migration and attachment. FASEB Journal 22 548-560. (doi:10.1096/fj.07-9308com)

Février B \& Raposo G 2004 Exosomes: endosomal-derived vesicles shipping extracellular messages. Current Opinion in Cell Biology 16 415-421.

Fleming JA, Song G, Choi Y, Spencer TE \& Bazer FW 2009 Interferon regulatory factor 6 (IRF6) is expressed in the ovine uterus and functions as a transcriptional activator. Molecular and Cellular Endocrinology 299 252-260. (doi:10.1016/j.mce.2008.10.025)

González-Navajas JM, Lee J, David M \& Raz E 2012 Immunomodulatory functions of type I interferons. Nature Reviews. Immunology 12 $125-135$.

Gray CA, Abbey CA, Beremand PD, Choi Y, Farmer JL, Adelson DL, Thomas TL, Bazer FW \& Spencer TE 2006 Identification of endometrial genes regulated by early pregnancy, progesterone, and interferon tau in the ovine uterus. Biology of Reproduction 74 383-394. (doi:10.1095/ biolreprod.105.046656)

György B, Szabó TG, Pásztoi M, Pál Z, Misják P, Aradi B, László V, Pállinger E, Pap E, Kittel A et al. 2011 Membrane vesicles, current stateof-the-art: emerging role of extracellular vesicles. Cellular and Molecular Life Sciences 68 2667-2688.

Hannafon BN \& Ding WQ 2013 Intercellular communication by exosomederived microRNAs in cancer. International Journal of Molecular Sciences 14 14240-14269. (doi:10.3390/ijms140714240)

Honda K, Yanai H, Negishi H, Asagiri M, Sato M, Mizutani T, Shimada N, Ohba Y, Takaoka A, Yoshida N et al. 2005 IRF-7 is the master regulator of type-I interferon-dependent immune responses. Nature $434772-777$. (doi:10.1038/nature03464)

Ito T, Wang YH \& Liu YJ 2005 Plasmacytoid dendritic cell precursors/type I interferon producing-cells sense viral infection by toll-like receptor (TLR) 7 and TLR9. Springer Seminars in Immunopathology 26 221-229. (doi:10.1007/s00281-004-0180-4) 
Johnson GA, Spencer TE, Burghardt RC \& Bazer FW 1999 Ovine osteopontin: I. Cloning and expression of mRNA in the uterus during periimplantation period. Biology of Reproduction 61 884-891. (doi:10. 1095/biolreprod61.4.884)

Kim MY \& Oglesbee M 2012 Virus-heat shock protein interaction and a novel axis for innate antiviral immunity. Cells 1 646-666. (doi:10.3390/ cells1030646)

Kumar H, Kawai T \& Akira S 2009 Toll-like receptors and innate immunity. Biochemical and Biophysical Research Communications 388 621-625. (doi:10.1016/j.bbrc.2009.08.062)

Kurt-Jones EA, Popova L, Kwinn L, Haynes LM, Jones LP, Tripp RA, Walsh EE, Freeman MW, Golenbock DT, Anderson LJ et al. 2000 Pattern recognition receptors TLR4 and CD14 mediate response to respiratory syncytial virus. Nature Immunology 1 398-401. (doi:10.1038/80833)

Leiser R \& Kaufmann P 1994 Placental structure: in a comparative aspect. Experimental and Clinical Endocrinology 102 122-134. (doi:10.1055/ s-0029-1211275)

Lotvall J \& Valadi H 2007 Cell to cell signalling via exosomes through esRNA. Cell Adhesion Migration 1 156-158.

Lyons-Weiler J, Watkins SC \& Morelli AE 2012 Mechanism of transfer of functional microRNAs between mouse dendritic cells via exosomes. Blood 119 756-766. (doi:10.1182/blood-2011-02-338004)

Macklon NS, Geraedts JP \& Fauser BC 2002 Conception to ongoing pregnancy: the "black box" of early pregnancy loss. Human Reproduction Update 8 333-343. (doi:10.1093/humupd/8.4.333)

Mansouri-Attia N, Oliveira LJ, Forde N, Fahey AG, Browne JA, Roche JF, Sandra O, Reinaud P, Lonergan P \& Fair T 2012 Pivotal role for monocytes/macrophages and dendritic cells in maternal immune response to the developing embryo in cattle. Biology of Reproduction 87 123. (doi:10.1095/biolreprod.112.101121)

Masciopinto F, Giovani C, Campagnoli S, Galli-Stampino L, Colombatto P, Brunetto M, Yen TSB, Houghton M, Pileri P \& Abrignani S 2004 Association of hepatitis $C$ virus envelope proteins with exosomes. European Journal of Immunology 34 2834-2842. (doi:10.1002/eji. 200424887)

Meckes DG Jr \& Raab-Traub N 2011 Microvesicles and viral infection. Journal of Virology 85 12844-12854. (doi:10.1128/JVI.05853-11)

Montecalvo A, Larregina AT, Shufesky WJ, Stolz DB, Sullivan ML, Karlsson JM, Baty CJ, Gibson GA, Erdos G, Wang Z et al. 2012 Mechanism of transfer of functional micro RNAs between mouse dendritic cells via exosomes. Blood 119 756-766. (doi:10.1182/blood2011-02-338004)

Morelli AE, Larregina AT, Shufesky WJ, Sullivan ML, Stolz DB, Papworth GD, Zahorchak AF, Logar AJ, Wang Z, Watkins SC et al. 2004 Endocytosis, intracellular sorting, and processing of exosomes by dendritic cells. Blood 104 3257-3266. (doi:10.1182/blood-2004-03-0824)

Ng YH, Rome S, Jalabert A, Forterre A, Singh $\mathrm{H}$, Hincks CS \& Salamonsen LA 2013 Endometrial exosomes/microvesicles in the uterine microenvironment: a new paradigm for embryo-endometrial cross talk at implantation. PLoS ONE 8 e58502. (doi:10.1371/journal.pone. 0058502)

Nguyen DG, Booth A, Gould SJ \& Hildreth JE 2003 Evidence that HIV budding in primarymacrophages occurs through the exosome release pathway. Journal of Biological Chemistry 278 52347-52354. (doi:10.1074/jbc.M309009200)

Oliveira LJ, Barreto RS, Perecin F, Mansouri-Attia N, Pereira FT \& Meirelles FV 2012 Modulation of maternal immune system during pregnancy in the cow. Reproduction in Domestic Animals 47 384-393. (doi:10.1111/j.1439-0531.2012.02102.x)

Palmarini M, Gray CA, Carpenter K, Fan H, Bazer FW \& Spencer TE 2001 Expression of endogenous betaretroviruses in the ovine uterus: effects of neonatal age, estrous cycle, pregnancy, and progesterone. Journal of Virology 75 11319-11327. (doi:10.1128/JVI.75.23.1131911327.2001)

Pegtel DM, Cosmopoulos K, Thorley-Lawson DA, van Eijndhoven MA, Hopmans ES, Lindenberg JL, de Grujil TD, Würdinger T \& Middeldorp JM 2010 Functional delivery of viral miRNAs via exosomes. PNAS 107 6328-6333. (doi:10.1073/pnas.0914843107)

Racicot K, Schmitt A \& Ott T 2012 The myxovirus-resistance protein, MX1, is a component of exosomes secreted by uterine epithelial cells. American Journal of Reproductive Immunology 67 498-505. (doi:10. 1111/j.1600-0897.2012.01109.x)

Ramprasad MP, Terpstra V, Kondratenko N, Quehenberger O \& Steinberg D 1996 Cell surface expression of mouse macrosialin and human CD68 and their role as macrophage receptors for oxidized low density lipoprotein. PNAS 93 14833-14838. (doi:10.1073/pnas.93.25.14833)

Raspotnig G, Fauler G, Jantscher A, Windischhofer W, Schachl K \& Leis HJ 1999 Colorimetric determination of cell numbers by Janus green staining. Analytical Biochemistry 275 74-83. (doi:10.1006/abio.1999.4309)

Reynolds LP \& Redmer DA 2001 Angiogenesis in the placenta. Biology of Reproduction 64 1033-1040. (doi:10.1095/biolreprod64.4.1033)

da Silveira JC, Veeramachaneni DN, Winger QA, Carnevale EM \& Bouma GJ 2012 Cell-secreted vesicles in equine ovarian follicular fluid contain miRNAs and proteins: a possible form of cell communication within the ovarian follicle. Biology of Reproduction 86 71. (doi:10.1095/ biolreprod.111.093252)

Simpson RJ, Jensen SS \& Lim JW 2008 Proteomic profiling of exosomes: current perspectives. Proteomics 8 4083-4099. (doi:10.1002/pmic. 200800109)

Spencer TE \& Bazer FW 1995 Temporal and spatial alterations in uterine estrogen receptor and progesterone receptor gene expression during the estrous cycle and early pregnancy in the ewe. Biology of Reproduction 53 1527-1543. (doi:10.1095/biolreprod53.6.1527)

Spencer TE \& Bazer FW 2004 Conceptus signals for establishment and maintenance of pregnancy. Reproductive Biology and Endocrinology $\mathbf{5}$ 2-49. (doi:10.1095/biolreprod.103.024133)

Spencer TE, Bartol FF, Bazer FW, Johnson GA \& Joyce MM 1999 Identification and characterization of glycosilation-dependent cell adhesion molecule 1-like protein expression in the ovine uterus. Biology of Reproduction 60 241-250. (doi:10.1095/biolreprod60.2.241)

Spencer TE, Johnson GA, Bazer FW \& Burghardt RC 2004 Implantation mechanisms: insights from the sheep. Reproduction 128 657-668. (doi:10.1530/rep.1.00398)

Trinchieri G 2010 Type I interferon: friend or foe? Journal of Experimental Medicine 207 2053-2063. (doi:10.1084/jem.20101664)

Vlassov AV, Magdaleno S, Setterquist R \& Conrad R 2012 Exosomes: current knowledge of their composition, biological functions, and diagnostic and therapeutic potentials. Biochimica et Biophysica Acta 1820 940-948. (doi:10.1016/j.bbagen.2012.03.017)

Wang R, Town T, Gokarn V, Flavell RA \& Chandawarkar RY 2006 HSP70 enhances macrophage phagocytosis by interaction with lipid raftassociated TLR-7 and upregulating p38 MAPK and PI3K pathways. Journal of Surgical Research 136 58-69. (doi:10.1016/j.jss.2006.06.003)

Wooding FB 1992 Current topic: the synepitheliochorial placenta of ruminants: binucleate cell fusions and hormone production. Placenta 13 101-113. (doi:10.1016/0143-4004(92)90025-O)

Received 8 September 2014

First decision 7 November 2014

Revised manuscript received 24 November 2014

Accepted 18 December 2014 